\title{
Das "listas negras": um estudo da prática discriminatória de contratação de empregados e sua afronta aos direitos fundamentais
}

\author{
The "black list": a study of discriminatory practice of hiring of employees and their \\ fundamental rights affront to
}

\section{Thatian Freitas Tonzar ${ }^{1}$ Lourival José de Oliveira ${ }^{2}$}

\section{Resumo}

\begin{abstract}
Apresentou-se um estudo acerca das práticas discriminatórias nas relações de trabalho, principalmente aquelas perpetradas no momento da seleção de candidatos à vaga de emprego. Constatou-se que 0 ato do empregador de selecionar empregados baseando-se no conteúdo das "listas negras" é uma prática discriminatória e que afronta diversos direitos fundamentais do empregado, como 0 direito à honra, à intimidade, direito ao trabalho e direito de ação. Verificou-se a colisão de direitos fundamentais, constatando, por meio do princípio da proporcionalidade e da ponderação de valores, que os direitos fundamentais do empregado, diretamente ligados à dignidade da pessoa humana, se sobrepõe a qualquer procedimento que individualize 0 empregado em razão de condutas passadas, muito mais quando se trata de procedimentos discriminatórios como os das "listas negras".
\end{abstract}

Palavras Chave: Discriminação; Contratação; "Listas Negras"; Afronta aos direitos fundamentais do empregado.

\section{Abstract}

She has performed a study on discriminatory practices in employment relationships, especially those perpetrated at the time of selection of candidates for the vacancy. It was found that the act of the employer to select employees based on the content of "black lists" is a discriminatory practice and that shame many fundamental rights of the employee, as the right to honor, privacy, right to work and right of action. There was a collision of fundamental rights, noting, through the principle of proportionality and balancing of values, that fundamental rights of the employee, directly linked to human dignity, overrides any procedure to individualize the employee because of past behavior, especially when it comes to discriminatory procedures as those of "blacklists".

\footnotetext{
${ }^{1}$ Acadêmica do 50 ano matutino do curso de Direito da Universidade Estadual de Londrina.

${ }^{2}$ Doutor em Direito (PUC-SP); professor associado da Universidade Estadual de Londrina; professor da FACCAR; professor do Curso de Mestrado da UNIMAR.
} 


\section{Das "listas negras": um estudo da prática discriminatória de contratação de empregados e sua afronta aos direitos fundamentais}

Keywords: Discrimination, Hiring, "blacklists" affront to the fundamental rights of the employee.

\section{Introdução}

A igualdade de tratamento e a conseqüente proibição de qualquer forma de discriminação vêm contempladas no texto constitucional e na legislação infraconstitucional brasileira, aplicando-se no âmbito de todas as relações humanas, inclusive na relação de trabalho.

0 direito ao trabalho vem definido na Constituição Federal como um dos direitos sociais elencados no artigo 60 , sendo proibido qualquer tipo de discriminação que tenha por objetivo reduzir ou limitar as oportunidades de acesso e manutenção ao emprego. Nesse sentido, 0 artigo 70, inciso XXX da Carta Magna estabelece como um dos direitos dos trabalhadores a "proibição de diferença de salários, de exercício de funções e de critério de admissão por motivos de sexo, idade, cor ou estado civil".

Muito embora as diversas formas de discriminação sejam repudiadas pela sociedade e expressamente proibidas pelo texto constitucional brasileiro, verifica-se nas relações de trabalho uma série de práticas, muitas vezes enrustidas, de discriminação tanto no processo seletivo do candidato à vaga de emprego, quanto na terminação do vínculo empregatício, através das despedidas arbitrárias.

Para Firmino Alves Lima, a crise do emprego e o excesso de oferta no mercado de trabalho propiciam ao inescrupuloso empregador um ambiente ainda mais favorável para tomar atitudes discriminatórias, estimulando-o a colocar em segundo plano critérios técnicos ou disciplinares nas suas escolhas (2006, p.15).

Assim, com o conseqüente aumento do seu poder de contratação em vista do grandioso número de candidatos que disputam o mercado de trabalho, o empregador utiliza-se por diversas vezes de critérios ilegítimos de discrímen, colocando em evidente condição de desvantagem alguns candidatos ou grupo de candidatos a vaga de emprego.

Nesse sentido, verifica-se na atualidade a divulgação e utilização das "Listas Negras", formadas a partir de uma base de dados relativos a trabalhadores que tenham ajuizado reclamatória trabalhista contra ex-empregadores e que vem servindo como critério de seleção dos candidatos à vaga de emprego. 
No entanto, apesar de o empregador pautar-se no poder diretivo, em sua liberdade de contratação, bem como no direito à informação, tal prática vai de encontro com alguns direitos do trabalhador, como o direito à privacidade, à honra, ao trabalho e o direito de ação. Assim, constata-se uma contraposição de direitos: de um lado os direitos e poderes do empregador e de outro os direitos fundamentais do empregado.

Nesse sentido, verifica-se a relevância e pertinência do tema, que advêm de sua atualidade e do contexto jurídico em que se insere, uma vez que suscita questionamentos de ordem constitucional, envolvendo conflito entre princípios e direitos fundamentais do empregado e do empregador.

O estudo em apreço busca justamente analisar tais práticas discriminatórias de contratação de empregados e cada um desses direitos em estado de colisão, avaliando, sob a luz da constituição, do parâmetro da proporcionalidade e da ponderação de valores, como um direito pode servir de limite em relação a outro.

\section{Das práticas discriminatórias nas relações de trabalho}

Para o melhor desenvolvimento do presente estudo, de início, cumpre tecer uma breve análise do que vem a ser discriminação e como ela se consubstancia nas diversas situações da relação de trabalho.

Para Maurício Godinho Delgado discriminação seria toda conduta por meio da qual “[...] se nega à pessoa, em face de critério injustamente desqualificante, tratamento compatível com o padrão jurídico assentado para a situação concreta por ela vivenciada." (2007, p. 774). Verifica-se, portanto, que a discriminação caracteriza-se pela conduta reprovável de negar um tratamento equânime à pessoa diante de sua situação concreta.

Analisando as considerações de Firmino Alves Lima a respeito do tema, depreendese que 0 ato discriminatório pressupõe alguns elementos para sua configuração. Dentre eles, a distinção desfavorável, que pode ser em virtude da percepção de menores vantagens ou da imposição de maiores ônus a determinadas pessoas ou grupo de pessoas; o motivo da distinção, que seria imprescindível para a caracterização da discriminação, mas que não teria necessidade de estar previsto em norma positivada, adotando-se o princípio que as previsões de motivos nos documentos legais são meramente indicativas; outro elemento seria que a prática discriminatória deve violar algum direito fundamental, e ainda que 0 ato 


\section{Das "listas negras": um estudo da prática discriminatória de contratação de empregados e sua afronta aos direitos fundamentais}

seja desprovido de qualquer critério de razoabilidade e objetividade (LIMA, 2006, p.109115).

Nas relações de trabalho, para a configuração de um ato discriminatório, a intenção do empregador não é considerada, bastando que se demonstre a existência de uma atitude que cause prejuízos ao trabalhador ou grupo de trabalhadores. Os direitos violados das vítimas de uma discriminação podem ser integrantes da própria relação de trabalho, podem se referir a direitos pessoais, ou de qualquer natureza, como por exemplo, no caso da discriminação de empregados que tenham ajuizado reclamatória trabalhista contra seus exempregadores, em evidente afronta ao direito de ingresso ao judiciário, o direito de ação.

Há que se registrar, no entanto, que as distinções realizadas em função das necessidades do trabalho ou qualificação do candidato, de caráter razoável, proporcional e justificável, não podem ser consideradas discriminação, vez que necessárias e justas ao desempenho do trabalho (BARROS, 2006, p.618).

Na prática, as situações de discriminação no âmbito das relações de trabalho podem ocorrer por motivo de idade, sexo, deficiência física, raça, religião, entre outros e podem se passar no momento da admissão ou contratação, com processos seletivos pautados em critérios discriminatórios; no decorrer da relação empregatícia, como no caso de diferenciação salarial entre homens e mulheres; ou mesmo no momento da terminação do vínculo, com a dispensa do empregado por motivo de uma opinião política divergente, por exemplo (COUTINHO; DELLEGRAVE NETO; GUNTHER, 2002. p.149).

0 presente estudo irá atentar-se às práticas discriminatórias perpetradas no momento da contratação do candidato à vaga de emprego, em que o empregador, pautando-se no poder diretivo, em sua liberdade de contratação, bem como no direito de informação quanto aos dados pessoais daquele com quem vai contratar, utiliza-se dos diversos mecanismos e avanços tecnológicos de acesso a dados informativos para, diante de tais informações, selecionar os candidatos à vaga de emprego.

Nesse sentido, surge recentemente a divulgação das denominadas "Listas Negras" ou "Listas Discriminatórias", as listas que contém dados de pessoas que tenham ajuizado reclamação trabalhista contra seus ex-empregadores e que contam características "negativas" em sua conduta profissional como, por exemplo, atos de insubordinação, 
registro em cadastros restritivos de crédito e até mesmo o recebimento de segurodesemprego.

\section{A divulgação das "listas discriminatórias"}

O momento da contratação de um empregado, segundo Thereza Cristina Gosdal, pode ser visto sob várias perspectivas. Do ponto de vista da empresa ou do empregador, o que importa é a busca do lucro, a redução dos gastos e a competitividade de seus produtos. Para tanto, o empregado a ser contratado deve possuir a melhor qualificação para o cargo e ainda deve representar menores custos e riscos ao empreendimento (GOSDAL, 2003, p. 227).

Nesse sentido, o empregador, na proteção de seus interesses e fundado em sua livre iniciativa e poder diretivo, imiscui-se em aspectos da vida pessoal do candidato à vaga de emprego de forma a buscar características ou condutas que, sob a sua óptica, podem ser negativas e prejudiciais ao empreendimento.

0 momento vivido atualmente de globalização de informações e de livre acesso a dados informativos através da rede mundial de computadores facilitou sobremaneira esta prática discriminatória de utilização de informações pessoais do candidato como critério de contratação.

Nesse sentido verifica-se constantemente a prática discriminatória perpetrada por empregadores no momento da seleção dos candidatos à vaga de emprego por meio das denominadas “Listas Negras” ou Listas Discriminatórias.

Como visto anteriormente, tais listas possuem dados de pessoas que tenham ajuizado reclamatória trabalhista contra seus ex-empregadores, ou mesmo que tenham figurado como testemunhas em processos trabalhistas, e que contam características "negativas" em sua conduta profissional.

O empregador, quando da utilização de tais listas, busca um candidato que represente os menores ricos possíveis para sua empresa e acaba selecionando aquele que não apresente tais características e condutas pessoais.

Para Raimundo Simão de M elo, através desse odioso ato discriminatório, praticado por "empregadores inescrupulosos", os trabalhadores somente têm acesso ao mercado de 


\section{Das "listas negras": um estudo da prática discriminatória de contratação de empregados e sua afronta aos direitos fundamentais}

trabalho caso não tenham sido autores em reclamações trabalhistas ajuizadas em face de antigos empregadores (2003, p.179).

Assim, a possibilidade de conseguir um emprego, que já é dificultada por um mercado de trabalho por demais competitivo, fica, ainda, condicionada a inexistência de ações judiciais movidas pelo candidato à vaga de emprego contra ex-empregadores, o que viola frontalmente o direito de ação dos trabalhadores, assegurado constitucionalmente no art. 5ํㅡ, inciso XXXV, assim como o próprio direito ao trabalho, disposto no art. 6ํ․

O livre acesso a dados pessoais nos sites dos Tribunais

Para a prática de tal forma de discriminação alguns maus empregadores utilizam-se, de forma fraudulenta, das tecnologias trazidas com o avanço da informática para o acesso a dados informativos de empregados que tenham ajuizado processos trabalhistas contra seus ex-empregadores. Recentemente vinham se utilizando da busca de informações processuais disponibilizadas nas homepages dos Tribunais Trabalhistas, com consultas formuladas através do nome das partes.

Nesse sentido, Raimundo Simão de M elo tece as seguintes considerações:

Quanto à primeira forma de discriminação acima aludida, por meio de consultas aos sites dos tribunais, essa triste realidade está a demonstrar, mais uma vez, que os avanços da ciência e o desenvolvimento tecnológico estão sendo utilizados para fins espúrios, diversos daqueles esperados pelos homens de bem (2003, p. 180).

Dessa forma, observa-se que o mundo moderno e virtual, possibilitado pelo desenvolvimento de tecnologias de ponta, tem possibilitado uma revolução dos costumes do homem e insere-se em todos os setores da sociedade, incluindo a comunidade jurídica. Com isso, verificou-se o desenvolvimento de homepages dos Tribunais e órgãos do Judiciário que facilitaram em muito a consulta e pesquisa de processos judiciais.

No entanto este "caminho sem volta", segundo as palavras de Mário Antônio Lobato de Paiva, deve ser visto com o máximo de cuidado para que este benefício, facilidade ou utilidade trazida pela tecnologia não venha a causar sérios prejuízos ao cidadão (2003, p. 257).

É, pois, que a consulta de informações processuais via rede mundial de 
computadores vem sendo utilizada para fins ilegítimos, como para seleção de candidatos a vaga de emprego de forma discriminatória, afrontando direitos constitucionalmente previstos.

Nesse sentido a comunidade jurídica em conjunto com especialistas da área de informática têm se preocupado com esta questão, visando coibir esta deletéria forma de discriminação na relação de trabalho e objetivando assegurar os direitos fundamentais dos trabalhadores.

Recentemente foi realizado o seminário internacional "Internet y Sistema Judicial em América Latina y el Caribe", promovido pelo Instituto de Invetigación para la Justicia Argentina, Corte Suprema da Costa Rica e International Development Research Centre do Canadá, oportunidade em que se discutiu sobre os benefícios e dificuldades advindas das home-pages dos Poderes Judiciais na rede e os programas de transparência e proteção de dados pessoais. Em um dos seminários, apresentado pelo brasileiro, Mário Antônio Lobato de Paiva, foi discutida justamente a problemática da busca livre disponibilizada pelos sites dos tribunais brasileiros, trazendo uma série de conseqüências negativas no que diz respeito à privacidade e intimidade das pessoas e principalmente do trabalhador, vez que põe em risco a conquista de um novo emprego (PAIVA, 2003, p. 257).

Com a ampla e irrestrita disponibilidade de dados processuais pelos sites dos tribunais trabalhistas, os maus empregadores acabam tendo fácil acesso aos dados dos trabalhadores que possuem ou possuíram algum tipo de ação contra seus ex-empregadores, funcionando como empecilho para obtenção de um novo emprego.

Entre as medidas tomadas no sentido de tentar evitar essa prática discriminatória, tem-se a Resolução no 310/2001, de 13 de dezembro de 2001, do Tribunal Regional do Trabalho da 24a Região, em que se determinou o bloqueio de consultas de processos, por busca livre pelo nome das partes, da página na internet e nos terminais de extratos dos órgãos da Justiça do Trabalho da respectiva Região, buscando evitar a consulta geral e indiscriminada, o que tornou 0 acesso restrito aos advogados ou às partes envolvidas, através de consultas efetuadas pelo nome do advogado, número de inscrição na Ordem dos Advogados do Brasil ou por número do processo (PAIVA, 2003, p. 257).

Seguindo neste mesmo sentido, o M inistério Público do Trabalho, na proteção do interesse público primário indisponível dos trabalhadores, também se articulou para ajudar 


\section{Das "listas negras": um estudo da prática discriminatória de contratação de empregados e sua afronta aos direitos fundamentais}

na coibição dessa prática discriminatória, tomando providência perante o Tribunal Superior do Trabalho para bloqueio da consulta por nome das partes às informações processuais disponibilizadas em sua homepage, bem como para emitir recomendação a todos os Tribunais Regionais para dessa forma também procederem (M ELO, 2003, p. 180).

Atualmente, todos os sítios eletrônicos dos Tribunais Regionais do Trabalho e do Tribunal Superior do Trabalho já contam com consultas apenas realizadas a partir do número do processo, nome do advogado ou número da $O A B$, sendo que em algumas homepages possibilita-se a consulta pelo nome da parte reclamada ou por seu CNPJ/CPF, como é o caso do TRT da 2ª Região.

\section{Conduta discriminatória e abuso de direito}

Conforme visto anteriormente, para a configuração de uma prática discriminatória faz-se necessário a verificação de alguns elementos: a distinção desfavorável, que pode ser em virtude da percepção de menores vantagens ou da imposição de maiores ônus a determinadas pessoas ou grupo de pessoas; o motivo da distinção; a violação de algum direito fundamental, e ainda que 0 ato seja desprovido de qualquer critério de razoabilidade e objetividade (LIM A, 2006, p.109-115).

Assim, cumpre analisar se a conduta de divulgar e utilizar as listas discriminatórias como critério de contratação de empregado configura-se em ato discriminatório.

A utilização de tais listas certamente tem o condão de impor uma distinção desfavorável àquele que tenha exercido o direito de ação contra um ex-empregador. Tem o efeito, injustificado, de alterar a igualdade de oportunidades ou de tratamento em matéria de acesso ao emprego ou profissão e viola frontalmente direitos fundamentais do empregado, como o direito à privacidade, intimidade e direito de ação. É ainda um ato desprovido de qualquer razoabilidade, vez que as características constantes nas "listas negras" e utilizadas como parâmetro para seleção do candidato à vaga de emprego não estão relacionadas ao trabalho a ser desempenhado nem com a capacidade do trabalhador para exercer o cargo.

Assim, a divulgação de tais listas deve ser considerada uma prática discriminatória e um abuso de direito, que além de ferir os princípios da dignidade da pessoa humana, da 
igualdade e não-discriminação, vai de encontro com uma série de direitos fundamentais do empregado.

Com relação à afronta aos direitos fundamentais do empregado através da divulgação das listas negras, a jurisprudência nacional assim já se manifestou:

LISTAGEM ELABORADA PELA EM PRESA COM DADOS PESSOAIS DO EX-EM PREGADO DIVULGAÇÃO - DANO MORAL INDEPENDENTE DE EVENTUAIS EFEITOS NA VIDA PROFISSIONAL DO TRABALHADOR.

A Corte Regional entendeu que há prejuízo à imagem, à intimidade e à dignidade do trabalhador cujos dados pessoais se encontram inseridos em um banco cadastral elaborado pela Reclamada, destinado a consulta por outras empresas em face de provável contratação, independentemente do resultado na vida funcional do mesmo. Assim, considerou de direito a indenização por dano moral. Diferentemente do que alegado pela Recorrente, não há no Acórdão Recorrido presunção de dano moral, mas simples afirmação da sua existência, diante do fato objetivo da inclusão do nome do autor em listagem que visava a consulta por outras empresas. A Corte concluiu que, independentemente do resultado sobre a vida funcional dos atingidos a divulgação de dados pessoais dos trabalhadores entre as empresas constituía per si o fator gerador de irrecusável prejuízo. Violação de lei não configurada (art. 5o, II, XIV, XXXIX e LVII da Constituição Federal). Nenhum dos julgados trazidos à colação contém entendimento acerca de idêntica questão (Súmulas 23 e 296/TST) (...). Agravo de Instrumento a que se nega provimento. (g.n.)

(BRASIL. Tribunal Superior do Trabalho. Processo: AIRR- no 558/2003-091-09-40.3, Relator: Juiz Convocado José Ronald C. Soares, Órgão Julgador: 2a Turma. Publicação: DJ data 23/03/07.)

Nesse sentido Mário Antonio Lobato de Paiva, ao tratar do assunto, declara ser esta forma de discriminação uma prática abusiva, conforme pode-se ver:

Discriminações que impeçam o acesso livre ao emprego com base em certidões expedidas pelo Serasa ou em virtude do empregado já ter ajuizado reclamação trabalhista contra seu antigo empregador são práticas abusivas e inconstitucionais que devem ser combatidas pela sociedade. (g.n.) (PAIVA, 2003, p. 258)

Trata-se de um abuso de direito porque a despeito de o empregador ter garantido constitucionalmente 0 direito a livre iniciativa e a propriedade privada, nos artigos 1 으, IV e 50, XXII, bem como o direito à informação quanto aos dados pessoais daquele com quem vai contratar, disciplinado no art. 5ㅇ, inciso XXXIII, tais direitos não são absolutos e devem sempre estar em consonância com a ordem constitucional.

\section{Os direitos fundamentais do empregado}




\section{Das "listas negras": um estudo da prática discriminatória de contratação de empregados e sua afronta aos direitos fundamentais}

O empregador, na direção das atividades de sua empresa, não pode jamais desconhecer direitos básicos do empregado previstos nas legislações trabalhistas, normas coletivas, regulamentos internos, contratos individuais e, sobretudo, na Constituição Federal, que prevê os direitos fundamentais enquanto cerne do ordenamento jurídico, aplicável a todas as relações humanas, entre as quais as relações jurídico-trabalhistas (BARROS, 2006, p. 589).

Assim, como se pôde observar, a prática discriminatória de divulgação e utilização das "Listas negras" vai de encontro com uma série de direitos fundamentais do empregado, tais como o direito à honra, a intimidade, o próprio direito ao trabalho e o direito de ação.

Quanto ao direito à honra, verifica-se que informações e dados divulgados pelo empregador a respeito de qualidades pessoais do empregado que 0 individualizam perante a sociedade, quando desabonadoras ou mesmo discriminatórias, configuram em violação ao seu direito à honra, vez que ofensivas a sua dignidade.

No que diz respeito ao direito à intimidade, Alice Monteiro de Barros trata-o como uma tutela dirigida contra as intromissões ilegítimas de terceiros, ou seja, é o direito de não ser conhecido em certos aspectos pelos demais (2006, p. 610).

Dessa forma, atos que consistem em pesquisar ou divulgar aspectos da vida pessoal do obreiro, ou mesmo do candidato à vaga de emprego, sem que possuam relevância para a atividade profissional, como no caso de investigação quanto à sua orientação sexual, nome incluído em cadastro restritivo de crédito ou divulgado em listas negras, configuram-se atentatórios ao direito à intimidade.

Segundo Thereza Cristina Gosdal, "o princípio da não-discriminação deve nortear todo o processo seletivo, constituindo limite à invasão da intimidade do empregado." (2003, p.241).

Por outro lado, é violado o direito ao trabalho. 0 sistema jurídico pátrio reconhece 0 direito social ao trabalho (art. 60 da Constituição Federal) como condição da existência digna do homem, concebido como uma projeção indissociável da personalidade do trabalhador, que se identifica com as condições existenciais necessárias ao desenvolvimento físico, psíquico e social do sujeito, não deixando de ser, pois, um direito fundamental (GEDIEL in: SARLET, 2003. p. 151). 
Tal direito é afrontado nas práticas seletivas dos candidatos à vaga de emprego fundadas em listas discriminatórias, vez que o trabalhador tem o seu direito de livre acesso ao trabalho vetado pelo futuro empregador, baseado em um critério de discrímen ilegítimo.

Por fim, resta evidente que a prática insidiosa de utilização de listas discriminatórias como critério de seleção de candidatos à vaga de emprego viola o direito de ação.

É, pois, que os trabalhadores somente têm acesso ao mercado de trabalho se não tiverem sido autores em reclamações trabalhistas ajuizadas em face de antigos empregadores, o que viola frontalmente o direito de ação, uma vez que se vêem compelidos a não pleitearem em juízo a defesa de seus direitos trabalhistas, quando lesados ou simplesmente ameaçados.

Os tribunais brasileiros nesse sentido têm se manifestado, como se pode observar da decisão adiante colacionada:

INFORM AÇÃO PRESTADA POR ANTIGO EM PREGADOR. TRABALHADOR APONTADO COMO IMPRÓPRIO PARA O EMPREGO POR TER AJUIZADO RECLAMAÇÃO TRABALHISTA. DANO MORAL DECORRENTE. A informação prestada por antigo empregador, no sentido de que determinada pessoa é imprópria para o trabalho em razão de contra ele ter movido ação trabalhista, eqüivale à "lista negra", prática assaz repudiada no âmbito desta Justiça Especializada. Ao sugerir fama de questionador e incapaz de prestar serviços àquele que busca judicialmente 0 reconhecimento de direitos que Ihe foram sonegados, a par de constituir evidente tentativa de obstar a continuidade de sua existência de forma digna, atinge-se 0 trabalhador em algo básico para o exercício da cidadania: o direito ao livre acesso ao Poder Judiciário. Dá-se, por essa via, uma destinação à liberdade de informação contrária ao Estado Democrático de Direito. Inequívoco dano à imagem advindo de conduta claramente discriminatória, que atenta contra a dignidade da pessoa humana, situação suficiente para atrair a incidência do disposto no inciso $X$ do artigo 5o da Constituição Federal não elidida pela posterior obtenção de nova relação empregatícia. (SANTA CATARINA. Tribunal Regional do Trabalho da 12a Região. Acórdão 3988/2006 -Relator: Juiz Gerson P. Taboada Conrado . Publicação: DJ/SC data: 31.03.2006, p. 320.)

E a doutrina também, como Raimundo Simão de Melo que tece as seguintes e oportunas considerações:

Com isso, a possibilidade de emprego fica condicionada à inexistência de ações judiciais movidas pelos candidatos às vagas existentes no mercado de trabalho, em evidente violação ao direito de ação dos trabalhadores, constitucionalmente assegurado (CF, art. 50, $X X X V)$, bem como ao próprio direito ao trabalho, que é um direito social (CF, art. 60). (2003, p. 179) 


\section{Das "listas negras": um estudo da prática discriminatória de contratação de empregados e sua afronta aos direitos fundamentais}

Diante da análise de tais direitos, cumpre analisar os direitos e poderes em que se fundam os empregadores para realizarem tais práticas seletivas de candidatos a vaga de emprego, para em ulterior momento analisar-se quais deles devem prevalecer.

\section{Os poderes e liberdades do empregador}

Inicialmente cumpre analisar o poder diretivo e a liberdade de contratação do empregador, prerrogativas legais das quais se utiliza para tomar as atitudes discriminatórias em estudo.

No que tange aos poderes do empregador no contrato de trabalho, Maurício Godinho Delgado, tratando-os de forma genérica como "poder empregatício", ensina que:

Poder empregatício é o conjunto de prerrogativas asseguradas pela ordem jurídica e tendencialmente concentradas na figura do empregador, para exercício no contexto da relação de emprego. Pode ser conceituado, ainda, como o conjunto de prerrogativas com respeito à direção, regulamentação, fiscalização e disciplinamento da economia interna à empresa e correspondente prestação de serviço (2007, p. 631).

Assim, o mencionado doutrinador entende que a expressão "poder empregatício" é a mais adequada para se referir ao fenômeno global do poder nas relações de emprego, o qual se desdobra em manifestações variadas, como o poder diretivo, o poder regulamentar, poder fiscalizatório e o poder disciplinar.

0 poder diretivo, que mais interessa ao presente estudo, pode ser entendido como o conjunto de prerrogativas, tendencialmente concentradas no empregador, dirigidas à organização da sua atividade e à determinação da forma pela qual ocorrerá a prestação dos serviços por parte do empregado.

Dessa forma, o poder diretivo pode ser entendido como aquele poder de organizar a sua atividade, seu negócio, estabelecendo qual a atividade a ser desenvolvida (se comercial, industrial, agrícola); o tipo de sociedade que se estabelecerá (sociedade limitada, por ações); o número de empregados, a forma de selecioná-los, o local e horário de trabalho, entre outros.

Somado à liberdade contratual, que "abrange os poderes de auto-regência de interesses, da livre discussão das condições contratuais e da escolha do tipo de contrato 
conveniente à atuação da vontade" (ROCHA; CAM BLER, 2002, p.33), o empregador se funda em tais direitos para livremente escolher quem contratar.

Por outro lado, o empregador ainda se utiliza do direito à informação, assegurado no art. 5, XVI da Constituição Federal, para justificar sua atitude.

No que se refere ao direito de informação mais em específico no contrato de trabalho, Eduardo Milléo Baracat esclarece que no momento da contratação tanto o empregador quanto 0 empregado têm o dever de informar os dados e elementos relevantes a determinar os respectivos consentimentos, dizendo ainda que tal dever de informação liga-se ao princípio da boa-fé no contrato de trabalho.

Nesse sentido, se o empregado ou o empregador deixarem de prestar informações relevantes à formação do contrato, não estarão agindo com a lealdade característica do princípio da boa-fé, que deve estar presente nas relações contratuais, inclusive nas empregatícias. Nesse diapasão, o empregador, entendo tratar-se de informação pertinente à formação do vínculo empregatício, faz uso do conteúdo das "Listas Negras" para selecionar seus candidatos.

\section{Da colisão de direitos fundamentais}

Os direitos fundamentais, enquanto direitos humanos constitucionalmente positivados, são polimórficos, dotados de um grau maior de abstração e amplitude, cujo conteúdo apenas é revelado no caso concreto e nas interações entre si ou com outros valores previstos na Constituição.

Dessa forma, em determinadas situações os direitos fundamentais entram em colisão entre si ou se chocam com outros valores ou bens constitucionalmente protegidos. Trata-se da colisão entre direitos fundamentais, fenômeno que se verifica "quando o exercício de um direito fundamental por parte de um titular impede ou embaraça o exercício de outro direito fundamental por parte de outro titular" (GRAU; CUNHA, 2003, p. 232).

Diante da breve reflexão acerca dos direitos fundamentais do empregado que são eventualmente violados quando da utilização das listas discriminatórias e dos direitos e poderes em que se fundam os empregadores para dessa forma agirem, percebe-se a relevância do presente estudo, visto que se verifica o fenômeno da colisão entre direitos fundamentais. 


\section{Das "listas negras": um estudo da prática discriminatória de contratação de empregados e sua afronta aos direitos fundamentais}

A prática discriminatória de (não) contratação de empregados fundada no conteúdo das "listas negras" suscita uma série de questionamentos de ordem constitucional, envolvendo conflito entre princípios e direitos fundamentais do empregado e do empregador, culminando na utilização do princípio da proporcionalidade ou razoabilidade e na ponderação de valores para solucioná-los.

Assim, questiona-se até que ponto a consulta a dados pessoais do candidato à vaga de emprego não se configura como uma prática discriminatória? Não teria direito 0 empregador à obtenção de dados relacionados àquele que possivelmente irá contratar? Não faria parte de seu poder diretivo e liberdade de contratação? Ou, por outro lado, não seria evidente afronta aos direitos fundamentais do empregado? Até que ponto o direito de um indivíduo esbarra na esfera jurídica alheia e sofre, assim, uma limitação? Há uma hierarquia entre estes direitos fundamentais?

Para a busca de respostas a tais questionamentos faz-se necessário o estudo com relação ao princípio da proporcionalidade enquanto princípio de interpretação constitucional e da ponderação de valores.

Proporcionalidade como princípio de interpretação

Para Paulo Bonavides, uma das aplicações mais proveitosas do princípio da proporcionalidade é a utilização do mesmo enquanto princípio de interpretação. Assim, toda vez que se verifica antagonismos entre direitos fundamentais, que protegem bens jurídicos igualmente relevantes, deve-se buscar uma solução conciliatória, para a qual o princípio da proporcionalidade se revela bastante apropriado (2004, p. 425).

O princípio enquanto um "guia à atividade interpretativa", segundo as palavras de Celso Ribeiro Bastos, apresenta-se aplicável não somente para elucidar certas questões conflituosas, mas para toda e qualquer interpretação, integrando, assim, o método de interpretação do Direito (BASTOS apud TAVARES, 2007, p. 683).

0 princípio da proporcionalidade é largamente utilizado na jurisprudência pátria, através do qual o juiz realiza o sopesamento ou ponderação dos direitos fundamentais e dos bens jurídicos que se encontram em estado de contradição, oferecendo ao caso concreto a solução ajustadora de coordenação dos bens em conflito, sempre primando pela 
manutenção do sistema jurídico e pela conformidade com a Constituição (CLÉVE; FREIRE In: GRAU; CUNHA, 2003, p. 232).

Assim, juntamente com este princípio, faz-se necessário o uso da técnica da ponderação de valores ou sopesamento.

Ponderação de valores

Luís Roberto Barroso, com a clareza que lhe é habitual, esclarece que a subsunção, enquanto fórmula de compreensão da aplicação do Direito (premissa maior -a normaincidindo sobre a premissa menor -o fato- e produzindo como conseqüência a aplicação do Direito ao caso concreto), já não é mais por si só suficiente para lidar com as situações jurídicas cada vez mais constantes na atualidade (2004, p. 356-357).

Assim, como no caso em destaque, em que se verifica um conjunto de normas que tutelam valores distintos entre si e apontam soluções diversas e contraditórias para a questão, a adoção da fórmula unidirecional da subsunção apontaria para a escolha de uma norma (a premissa maior), descartando as demais. No entanto, esta solução não encontra respaldo constitucional, uma vez que afronta o princípio da unidade da Constituição, de tal sorte que 0 intérprete não pode simplesmente escolher uma norma e descartar as demais.

Em conseqüência, a interpretação constitucional se viu na necessidade de desenvolver técnicas capazes de lidar com o fato de a Constituição ser um documento dialético, que tutela interesses e valores que freqüentemente entram em colisão. É nesse diapasão que a doutrina desenvolve a técnica da ponderação ou balanceamento.

Conforme se vê na explanação de Luís Roberto Barroso:

A ponderação consiste, portanto, em uma técnica de decisão jurídica aplicável a casos difíceis, em relação aos quais a subsunção se mostrou insuficiente, especialmente quando uma situação concreta dá ensejo à aplicação de normas de mesma hierarquia que indicam soluções diferenciadas ( 2004, p. 358).

Considerando que os direitos fundamentais expressam valores igualmente significantes, a sua simultânea proteção a titulares diversos pode gerar aparentes antinomias quando da aplicação ao caso concreto (HASSON, 2003, p. 121). Assim, a ponderação ou balanceamento compreende método hábil a solucionar colisão entre direitos fundamentais ou entre direitos fundamentais e bens constitucionalmente protegidos (CLÉVE; FREIRE In: GRAU; CUNHA, 2003, p.241). 


\section{Das "listas negras": um estudo da prática discriminatória de contratação de empregados e sua afronta aos direitos fundamentais}

Gomes Canotilho esclarece que há "uma colisão autêntica de direitos fundamentais quando o exercício de um direito fundamental por parte do seu titular colide com o exercício do direito fundamental por parte de outro titular" (2003, p. 1271).

Assim, as questões atinentes ao presente estudo se enquadram justamente em uma colisão de direitos fundamentais, uma vez que, de um lado, se encontram direitos fundamentais do empregado, como o direito à dignidade, à igualdade, não discriminação, direitos da personalidade e o direito de ação; sendo que do outro, situam-se os direitos fundamentais do empregador de livre iniciativa privada, liberdade de contratação e direito à informação.

Através do método da ponderação, a atividade interpretativa inicia-se por uma reconstrução e qualificação dos interesses contrapostos, detectando no sistema as normas relevantes para solução do caso, identificando eventuais conflitos entre elas; após, passa-se ao exame dos fatos e circunstâncias concretas do caso e por fim, verifica-se o exercício em específico da ponderação, que vai propiciar um equilíbrio entre os direitos que estão em estado de tensão, atribuindo-Ihes pesos ou valores, concluindo pela escolha daquele direito que deve preponderar no caso.

Todo esse processo interpretativo deve estar fundado no princípio da proporcionalidade, vez que a ponderação de valores não pode ser vista como "um convite para o exercício indiscriminado de ativismo judicial". (BARROSO, 2004, p. 358) De forma que a discricionariedade judicial encontra-se limitada aos casos em que o sistema jurídico não tenha sido suficiente para oferecer uma solução em tese e ainda é controlada pelo exame da argumentação, verificando-se a correção dos argumentos apresentados ou ao menos a racionalidade do raciocínio desenvolvido no caso.

\section{As listas negras e a violação aos direitos fundamentais do empregado}

Com relação ao caso da divulgação e utilização das "Listas Negras", a ponderação de valores e a adoção do princípio da proporcionalidade tornam-se necessários na medida em que a exigência de não ajuizamento de ações trabalhistas contra ex-empregadores para fins de contratação funda-se em direitos e poderes do empregador que não são absolutos e devem estar em consonância com a ordem jurídica constitucional, havendo, portanto, a sua 
colisão com uma série de direitos fundamentais que se ligam diretamente à dignidade do trabalhador.

A solução para esse conflito aparente de normas deve ser dada pelo aplicador do Direito, diante das peculiaridades do caso concreto, verificando inicialmente se 0 ato do empregador de seleção do candidato encontra-se guiado pela proporcionalidade para, em um segundo momento, analisar o conflito em si dos direitos e valores, baseando-se na ponderação e na proporcionalidade enquanto princípio de interpretação.

O princípio da proporcionalidade possui três elementos, conteúdos parciais ou subprincípios, quais sejam, a conformidade ou adequação, a necessidade e a proporcionalidade em sentido estrito.

Assim, cumpre verificar se a medida de seleção de empregados fundada no conteúdo das Listas Discriminatórias é adequada ou pertinente a atingir o fim almejado, que é a contratação do candidato a uma vaga de emprego; verificar se este ato de seleção se faz necessário, considerando que as características ou qualidades pessoais do candidato divulgadas em tais listas não influenciam diretamente na atividade da empresa ou no exercício da função a ser desenvolvida e ainda observar quais são os interesses em jogo, sopesando-os e buscando a justa medida entre os meios e os fins.

Como 0 ato de seleção de candidatos envolve uma série de direitos e valores em estado de conflito, como já foi amplamente analisado, resta nesse momento analisar quais deles devem prevalecer, primando-se sempre pela conformidade e unidade constitucional.

Nesse sentido, devem-se estabelecer os pesos e valores dos direitos em choque, então, os direitos do trabalhador, ligados diretamente a dignidade da pessoa humana, claramente devem prevalecer sobre direitos de cunho privado, como a liberdade de contratação e poder diretivo, mesmo porque, tais direitos devem estar em consonância com a função social, que torna o contrato e a propriedade privada elementos socialmente relevantes, limitando o exercício de tais liberdades.

Por outro lado, segundo Paulo Eduardo V. Oliveira, o contrato de trabalho não se resume a um conteúdo patrimonial (pagamento de salário mediante a contraprestação do trabalho), mas possui uma dimensão muito maior, envolvendo o direito e a obrigação de respeito à dignidade das partes, principalmente do empregado (2002, p. 87). 


\section{Das "listas negras": um estudo da prática discriminatória de contratação de empregados e sua afronta aos direitos fundamentais}

As normas laborais bem como a própria Constituição Federal trazem normas de proteção à dignidade e aos direitos personalíssimos do empregado, que acabam restringindo o exercício da autonomia contratual pelo empregador e integrando o conteúdo do contrato de trabalho.

No caso das "listas negras", verifica-se que a despeito de ter o empregador a liberdade contratual, podendo escolher com quem contratar, e a livre iniciativa para exercer a atividade econômica, tais liberdades devem estar em consonância com o princípio da função social e respeitar a dignidade da pessoa humana.

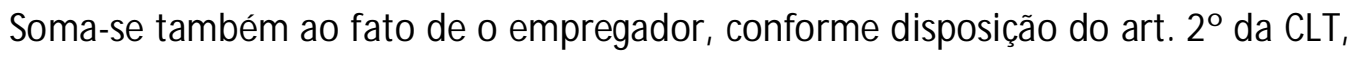
assumir os riscos da atividade empresarial. Assim, a despeito de 0 empreendedor poder considerar um risco à sua atividade a contratação de um empregado que já ajuizou reclamatória trabalhista contra ex-empregador, este risco é um ônus seu. Nesse sentido, Marco Túlio Viana, tratando da discriminação quanto à verificação de antecedentes criminais de candidatos à vaga de emprego, que, guardadas as devidas proporções, cabe no presente caso, assevera que:

É verdade que a contratação de um trabalhador nessa situação implica algum risco à empresa. Mas esse risco não será maior do que a empresa corre diariamente, como o de um concorrente baixar os preços, um fornecedor se atrasar na entrega ou um cliente denunciá-lo ao Procon (VIANA apud GOSDAL, 2003, p. 245).

Então, tanto os riscos do negócio quanto o respeito ao princípio da função social do contrato, que exige que o empregador atenda na contratação aos ditames da justiça social, não condizem com uma prática discriminatória de seleção de candidatos à vaga de emprego.

Como esclarece José Antônio Peres Gediel, a atividade econômica, enquanto expressão e exercício da livre iniciativa e da propriedade privada, somente se torna viável ao se apresentar conformada pelo respeito à dignidade da pessoa humana e pelos direitos fundamentais (GEDIEL In: SARLET, 2003. p.156).

Portanto, diante de uma análise fundada na ponderação dos valores em conflito e no princípio da proporcionalidade, verifica-se, na prática discriminatória em estudo, a violação dos direitos fundamentais do empregado o que pode gerar, inclusive, o direito a reparação por danos morais, tema que não se pretende abordar nesse momento, vez que 
comporta estudo diferenciado, inclusive quanto aos mecanismos preventivos e coibitivos de tais práticas, considerando que a tendência moderna, em termos de reparação de danos morais, é justamente a prevenção, em especial porque os danos de natureza imaterial não se coadunam com a tutela ressarcitória, por não ser mecanismo suficiente a proporcionar ao lesado a volta ao status quo ante (BARROS, 2008, p. 241).

\section{Conclusão}

Constatou-se, no presente estudo, que 0 ato do empregador de selecionar empregados baseando-se no conteúdo das "listas negras" é uma insidiosa prática discriminatória, que apesar de não constar expressamente nos textos legais como um fator ilegítimo de discrímen, deve ser abolida pelo sistema jurídico, uma vez que os fatores elencados são de cunho elucidativo, e não taxativo, considerando que o dispositivo genérico do art. 3, IV da CF estabelece o repúdio a "quaisquer outras formas de discriminação".

Dessa forma, verificou-se que a utilização de listas discriminatórias tem o condão de impor uma distinção desfavorável àquele que tenha exercido o direito de ação contra um exempregador. Tem o efeito, injustificado, de alterar a igualdade de oportunidades ou de tratamento em matéria de acesso ao emprego ou profissão e viola frontalmente direitos fundamentais do empregado, como o direito à privacidade, intimidade, direito ao trabalho e direito de ação.

Assim, concluiu-se que, a despeito de ter o empregador o direito à informação, a liberdade contratual, bem como a livre iniciativa para exercer a atividade econômica, tais direitos e liberdades não são absolutos e devem estar em consonância com a ordem jurídica constitucional, havendo, portanto, a sua colisão com uma série de direitos fundamentais do empregado.

Portanto, a partir de uma análise fundada no princípio da proporcionalidade, observou-se que tal ato do empregador é desprovido de qualquer razoabilidade, vez que as características constantes nas "listas negras" e utilizadas como parâmetro para seleção do candidato à vaga de emprego não estão relacionadas ao trabalho a ser desempenhado nem com a capacidade do trabalhador para exercer o cargo.

Ademais, constatou-se, por meio de uma análise dos pesos e valores dos direitos em choque (ponderação de valores), que os direitos do trabalhador, ligados diretamente a 
dignidade da pessoa humana, devem prevalecer sobre direitos de cunho privado, como 0

poder diretivo e a liberdade de contratação, mesmo porque tais direitos devem observar sua função social.

Nesta senda, constatou-se que tal prática discriminatória, além de afrontar os princípios da dignidade da pessoa humana, da igualdade e não-discriminação, viola direitos fundamentais do empregado e que pode gerar o direito a reparação por danos morais.

\section{Referências}

ALESSI, Marcelo. "Discriminação no Direito do Trabalho: Aspectos Legais e Jurisprudenciais". In: COUTINHO, Aldacy Rachid; DELLEGRAVE NETO, José Affonso; GUNTHER, Luiz Eduardo (coord). Transformações do Direito do Trabalho.1.ed.2.tir. Curitiba: Juruá, 2002.

BARROS, Alice M onteiro de. Curso de Direito do Trabalho. 2. ed. São Paulo: LTr, 2006.

BARROS, Renato da Costa Lino de Goes. Assédio Moral: análise sob a luz dos aspectos configurativos e probatórios deste fenômeno social. Revista de Direito do Trabalho. São Paulo, ano 34, n. 129, p. 241, jan/mar, 2008.

BARROSO, Luís Roberto. Interpretação e Aplicação da Constituição: fundamentos de uma dogmática constitucional transformadora. 6. ed. rev. atual. e ampl. São Paulo: Saraiva, 2004.

BONAVIDES, Paulo. Curso de Direito Constitucional. 14.ed. São Paulo: Malheiros Editores Ltda, 2004.

BRASIL. Constituição (1988). Constituição da República Federativa do Brasil. Brasília, DF, 1988.

BRASIL. Tribunal Superior do Trabalho. Processo: AIRR- no 558/2003- 091-09-40.3, Relator: Juiz Convocado José Ronald C. Soares, Órgão Julgador: 2a Turma. Publicação: DJ data 23/03/07. Disponível em: «ttp:// www.tst.gov.br>Acesso em: 12 abr. 2008.

CANOTILHO, José Joaquim Gomes. Direito Constitucional e Teoria da Constituição. 7. ed. Coimbra: Almedina, 2003.

DELGADO, Maurício Godinho. Curso de Direito do Trabalho. 6.ed. São Paulo: LTr, 2007.

GEDIEL, José Antônio Peres. "A irrenunciabilidade a direitos da personalidade pelo trabalhador". In: SARLET, Ingo Wolfgang (org).Constituição, Direitos Fundamentais e Direito 
Privado. Porto Alegre: Livraria do Advogado Editora, 2003.

GOSDAL, Thereza Cristina. Antecedentes Criminais e Discriminação no Trabalho, Revista do Tribunal Regional do Trabalho da 9a Região, Curitiba, ano 28, n.49, jan/jun, 2003.

HASSON, Roland (Coord). Direito dos Trabalhadores \& Direitos Fundamentais. Curitiba: Juruá, 2003.

LIM A, Firmino Alves. M ecanismos Antidiscriminatórios nas Relações de Trabalho. São Paulo: LTr, 2006.

M ELO, Raimundo Simão de. Discriminação, Lista Negra e Direito de Ação. Revista de Direito do Trabalho, São Paulo, ano 29, n. 109, jan-mar/2003.

M INAS GERAIS. Tribunal Regional do Trabalho da 3a Região. Processo: RO no: 00951/2005 Número Único Proc: RO - 00951-2005-015-03-00-4. Relator: Fernando Luiz Gonçalves Rios Neto Órgão Julgador: Quarta Turma. Publicação: DJM G Data: 15-07-2006 p. 13. Disponível em: 〈http://as1.trt3.jus.br/jurisprudencia>. Acesso em: 12 fev. 2008.

NEGREIROS, Teresa. Teoria do Contrato: novos paradigmas. 2. ed. Rio de Janeiro: Renovar, 2006.

OLIVEIRA, Paulo Eduardo Vieira. O Dano Pessoal no Direito do Trabalho. São Paulo: LTr, 2002.

PAIVA, Mário Antônio Lobato de. Responsabilidade Civil do Estado por Danos Provenientes de Veiculação de Dados nos Sites dos Tribunais. Revista de Direito do Trabalho, São Paulo, ano 29, n.112, p. out-dez/2003.

ROCHA, Silvio Luís Ferreira da; CAMBLER, Everaldo Augusto (coord.). Curso Avançado de Direito Civil, v. 3: Contratos. São Paulo: Revista dos Tribunais, 2002.

SANTA CATARINA. Tribunal Regional do Trabalho da 12a Região. Acórdão 3988/2006 Relator: Juiz Gerson P. Taboada Conrado . Publicação: DJ/SC data: 31.03.2006, p. 320. Disponível em: বttp://www3.trt12.gov.br/juris/scripts/form-juris.asp> Acesso em: 20 mar. 2008.

TAVARES, André Ramos. Curso de Direito Constitucional. 5.ed. rev. e atual. São Paulo: Saraiva, 2007. 